\title{
Bilateral Transverse Sinus Angioplasty for the Treatment of Idiopathic Intracranial Hypertension - Case Report and Literature Review
}

\section{Angioplastia de Seio Transverso Bilateral para Tratamento de Hipertensão Intracraniana Idiopatica - Relato de caso e Revisão da literatura}

Luciano B. Manzato ${ }^{10}$ Paulo Moacir Mesquita Filho ${ }^{2}$ Leonardo Frighetto ${ }^{2}$ Nério Dutra Azambuja jr. ${ }^{2}$ Rafael Cordeiro ${ }^{3}$ José Ricardo Vanzin ${ }^{1}$

${ }^{1}$ Neurology and Neurosurgery Service, Department of Neurosurgery and Interventional Neuroradiology, Hospital de Clínicas de Passo Fundo, Passo Fundo, RS, Brazil

Address for correspondence Luciano B. Manzato, MD, Rua Gabriel Bastos, 13, Passo fundo, RS, 99020100 , Brazil

2 Neurology and Neurosurgery Service, Department of Neurosurgery, (e-mail: Ibmanzato@hotmail.com).

Hospital de Clínicas de Passo Fundo, Passo Fundo, RS, Brazil

3 Department of Neurosurgery, Hospital de Clínicas de Passo Fundo,

Passo Fundo, RS, Brazil

Arq Bras Neurocir 2019;38:203-209.

\begin{abstract}
Keywords

- intracranial hypertension

- angioplasty

- venous sinus stenosis

\section{Resumo}

Palavras-chave

- hipertensão intracraniana

- angioplastia

- estenose seio transverso

Idiopathic intracranial hypertension (IIH) is a disease characterized by an increase in intracranial pressure, without presence of parenchymal lesions or hydrocephalus that justify it. Over $90 \%$ of cases there is association with stenosis of the dural venous sinuses. It is characterized by headache, tinidus, nausea, vomiting and visual disturbances. Initial treatment is clinical and when it fails there is indication of invasive procedures, among them shunts and fenestration of the optic nerve sheath. Angioplasty of dural venous sinuses, when indicated, has shown an alternative with better results and less complications. We report a case of a female patient, with 27 years old, diagnosed with $\mathrm{IIH}$ and bilateral transverse sinus stenosis, which was treated by bilateral stenting and total resolution of symptoms. Besides describing the case we review the literature about the subject.

Hipertensão intracraniana idiopática (HII) é uma doença caracterizada pelo aumento da pressão intracraniana, sem a presença de lesões parenquimatosas ou hidrocefalia que a justifiquem. Em > 90\% dos casos, há relação com estenose de seios venosos durais. O quadro clinico é caracterizado por cefaleia, tinnitus, náuseas, vômitos e distúrbios visuais. O tratamento inicial consiste em uma modalidade clinica, e quando esta é ineficaz, há indicação de procedimentos invasivos, dentre os quais estão as
\end{abstract}

(1DLuciano B. Manzato's ORCID is https://orcid.org/0000-0002-42913831.

received

February 21, 2019

accepted

April 17, 2019
DOI https://doi.org/

10.1055/s-0039-1692122.

ISSN 0103-5355.
Copyright @ 2019 by Thieme Revinter

Publicações Ltda, Rio de Janeiro, Brazil
License terms

(c) $(1) \$$ 
derivações liquóricas e a fenestração da bainha do nervo óptico. A angioplastia dos seios venosos, quando indicada, mostra-se uma alternativa com melhores resultados e com menos complicações. Relatamos o caso de uma paciente de 27 anos com diagnóstico de $\mathrm{HII}$ e estenose de seio transverso bilateral na qual o tratamento realizado foi o implante de stents, com melhora completa dos sintomas. Além do relato de caso, revisamos a literatura a respeito do assunto.

\section{Introduction}

Idiopathic intracranial hypertension (IIH) is characterized by increased intracranial pressure (ICP) without the presence of cerebral parenchymal lesions or hydrocephalus to explain it. More than $90 \%$ of the cases are associated with stenosis of the dural venous sinuses. ${ }^{1}$ Its pathophysiology is poorly defined, and its etiology is believed to be multifactorial, leading to changes that modify cerebrospinal fluid (CSF) dynamics, thus causing increased CSF production or reduced CSF absorption. $^{2}$ Although IIH is considered a benign disease, it can cause irreversible visual impairment in between 10 and 20\% of the patients. ${ }^{3}$ The estimated incidence is of 1.2 cases per 100,000 individuals per year in the general population, and the prevalence is highest in overweight young women. ${ }^{4}$

The clinical picture is characterized by headache of variable intensity (present in up to $94 \%$ of patients); tinnitus, which can be unilateral or bilateral; nausea and vomiting; and, most importantly, visual disturbances. These include diplopia (due to involvement of the abducens nerve), papilledema (reflecting increased ICP), and, in some cases, reduction of visual acuity due to chronification. ${ }^{5}$ The diagnosis is made through a multidisciplinary neuro-ophthalmological evaluation, with demonstration of papilledema through fundoscopy and of increased ICP by lumbar puncture with measurement of CSF pressure. ${ }^{6}$ Concomitantly, other causes of intracranial hypertension should be ruled out through neuroimaging. Magnetic resonance imaging (MRI) of the brain may demonstrate secondary signs of IIH, such as empty sella, posterior flattening of the globe, and increased subarachnoid space around the optic nerve. ${ }^{7}$

Angioplasty of the venous sinuses, when indicated, is an alternative that provides better outcomes with fewer complications than conventional surgical treatments. We report a case of IIH treated successfully by stent placement for bilateral transverse sinus stenosis, and briefly review the relevant literature.

\section{Case Report}

A 27-year-old woman with no past medical history, no comorbidities, and not overweight was referred to the neurosurgery department by her ophthalmologist. She reported a 1-month history of progressively worsening, nonradiating, nontension-type bifrontal headache without triggering factors. She reported having sought urgent care several times due to recurrent headache. She noticed a gradual deterioration of visual acuity and then saw an ophthalmologist, who detected bilateral papilledema and promptly referred her to our service for evaluation.

A magnetic resonance imaging (MRI) of the brain showed no space-occupying lesions and no signs of hydrocephalus or of demyelination. Magnetic resonance angiography of the cerebral circulation ruled out cerebral venous thrombosis, but demonstrated possible bilateral transverse sinus stenosis.

A diagnosis of IIH was suggested due to the refractory symptoms of the patient, to the neuroimaging findings, to the evidence of increased ICP, and to the persistent visual deficit. To confirm this hypothesis, lumbar puncture was performed, which showed an opening CSF pressure of $37 \mathrm{cmH}_{2} \mathrm{O}$. Approximately $40 \mathrm{~mL}$ of CSF were drained; after the procedure, the patient reported substantial improvement of the headache.

We decided on a trial of clinical treatment and prescribed acetazolamide $250 \mathrm{mg}$ every 6 hours. There was slight improvement of the headache, but no improvement of the visual deficit; in addition, the patient experienced several adverse effects, including abdominal discomfort, nausea, vomiting, and postural hypotension.

After discussing additional therapeutic options with the patient, we decided to perform angiography to determine the trans-stenotic pressure gradient. If there was a change of $>8 \mathrm{mmHg}$, stent placement would be indicated. The angiogram revealed bilateral transverse sinus stenosis ( - Fig. 1) with a prestenosis venous pressure of $37 \mathrm{mmHg}$ and a poststenosis pressure of $9 \mathrm{mmHg}$ on the right, and a prestenosis pressure of $35 \mathrm{mmHg}$ and a poststenosis pressure of $8 \mathrm{mmHg}$ on the left (pressure differential, $28 \mathrm{mmHg}$ on the right and $27 \mathrm{mmHg}$ on the left). Intravenous ultrasound confirmed bilateral venous narrowing ( - Fig. 2). With confirmation of the large bilateral pre- and poststenosis pressure gradient, stents were placed in both transverse sinuses. After the procedure, a new pressure gradient measurement was performed and revealed a significant reduction, with a prestenosis pressure of $11 \mathrm{mmHg}$ and a poststenosis pressure of $9 \mathrm{mmHg}$ in the right transverse sinus. On the left, the prestenosis and poststenosis measurement was $11 \mathrm{mmHg}$ and $10 \mathrm{mmHg}$, respectively. In the immediate postoperative period, the patient reported slight worsening of her headache, possibly due to the manipulation of the venous system, which improved gradually with corticosteroids. She had an uneventful course and was discharged early free of pain.

At the outpatient follow-up 2 weeks after the procedure, the patient reported no pain. Recovery of visual acuity 


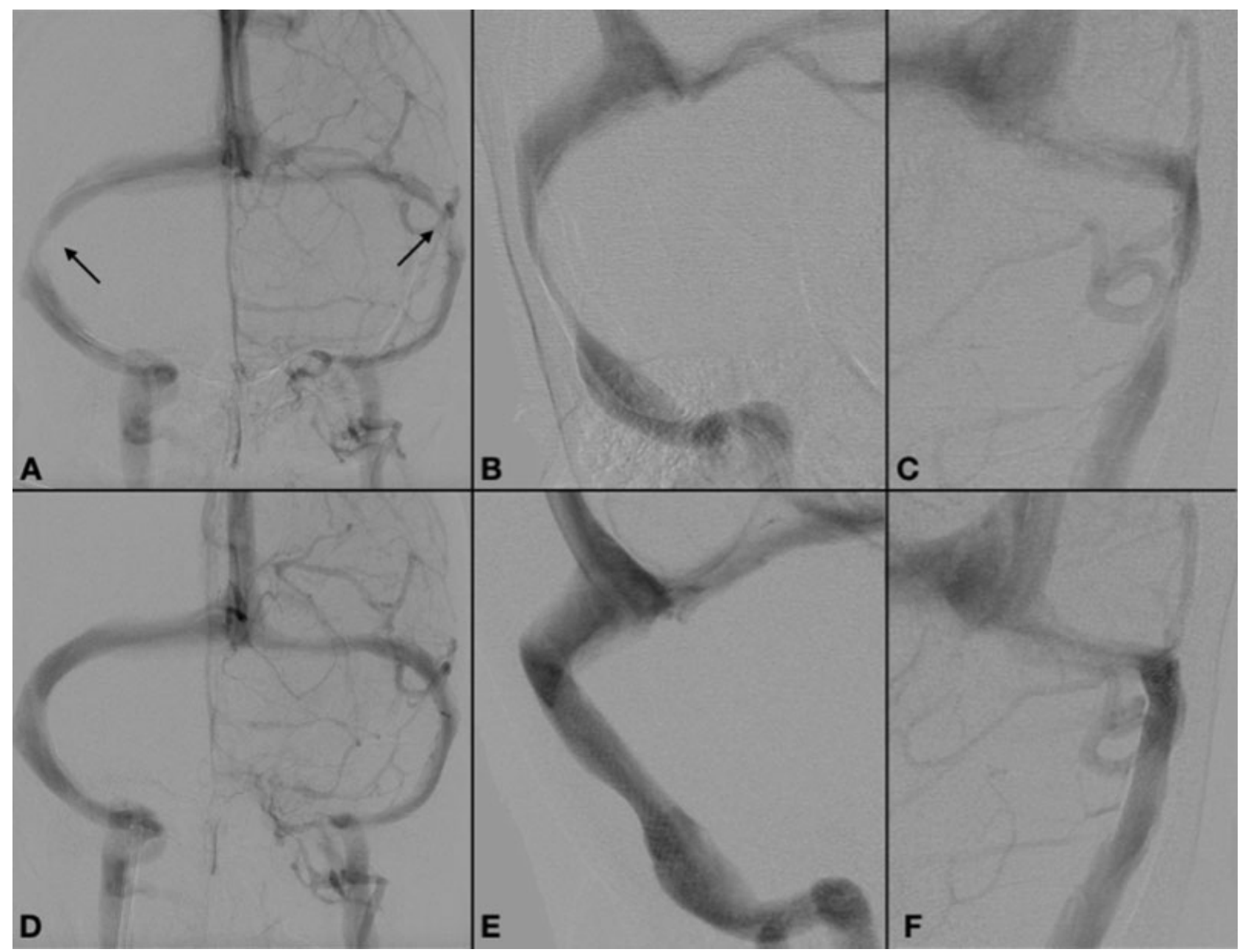

Fig. 1 Venography before stent implantation demonstrating bilateral transverse sinus stenosis - arrows (A). Right transverse sinus stenosis (B). Left transverse sinus stenosis (C). Images after stent implantation (D). Postoperative right transverse sinus (E). Postoperative left transverse sinus $(F)$.

followed at $\sim 1$ month. Repeat ophthalmologic evaluation demonstrated complete resolution of the papilledema. At the time of writing, 6 months after the procedure, the patient is symptom-free. Clinical follow-up with the neurosurgery and ophthalmology teams is ongoing; we have not performed control angiogram or lumbar puncture, which would be unjustifiable in an asymptomatic patient.

\section{Procedure}

The patient began dual antiplatelet therapy (aspirin $100 \mathrm{mg} /$ day and clopidogrel $75 \mathrm{mg} /$ day) 5 days before the procedure. First, conscious sedation was administered for the measurement of pressure gradients. Access was achieved through the right femoral artery with a $5 \mathrm{~F}$ sheath for angiographic control and road mapping, and through the left femoral vein with a $6 \mathrm{~F}$ sheath for stent placement. A bolus injection of $5000 \mathrm{IU}$ of unfractionated heparin was administered, and a $6 \mathrm{~F}$ guide catheter was advanced to the right jugular bulb. A 0.027-inch Rebar microcatheter (Medtronic, Minneapolis, MN, USA) was passed coaxially, over a 0.014-inch Hybrid microguidewire (Balt Extrusion, Montmorency, France), to the sites designated for pre- and poststenosis pressure measurement, with the results described above.

With the confirmation of gradients $>8 \mathrm{mmHg}$, general anesthesia was induced for stent placement. The $6 \mathrm{~F}$ venous introducer was replaced with a $60-\mathrm{cm} 10 \mathrm{~F}$ sheath, and a $90-$ $\mathrm{cm} 8 \mathrm{~F}$ guide catheter was passed coaxially over a 0.35 -inch hydrophilic guidewire and was advanced to the right jugular bulb. Then, a 0.014-inch BMW Extra Support microguide (Abbott, Chicago, IL, USA) was passed up to the poststenotic segment of the left transverse sinus. A $9 \times 30 \mathrm{~mm}$ Wallstent (Boston Scientific, Marlborough, MA, USA) was navigated and deployed to cover the stenosis on the left side. A $9 \times 40 \mathrm{~mm}$ Wallstent (Boston Scientific, Marlborough, MA, USA) was then navigated through the same system and

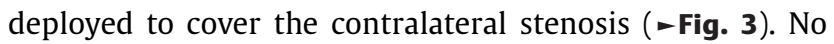
balloon dilation was performed. Finally, a 0.027-inch Rebar catheter (Medtronic, Minneapolis, MN, USA) was again navigated for repeat measurement of the venous pressures, which showed normalization of the gradients. The patient completed a 30-day course of dual antiplatelet therapy, after which clopidogrel was discontinued. She continues to take aspirin (100 mg/day). 


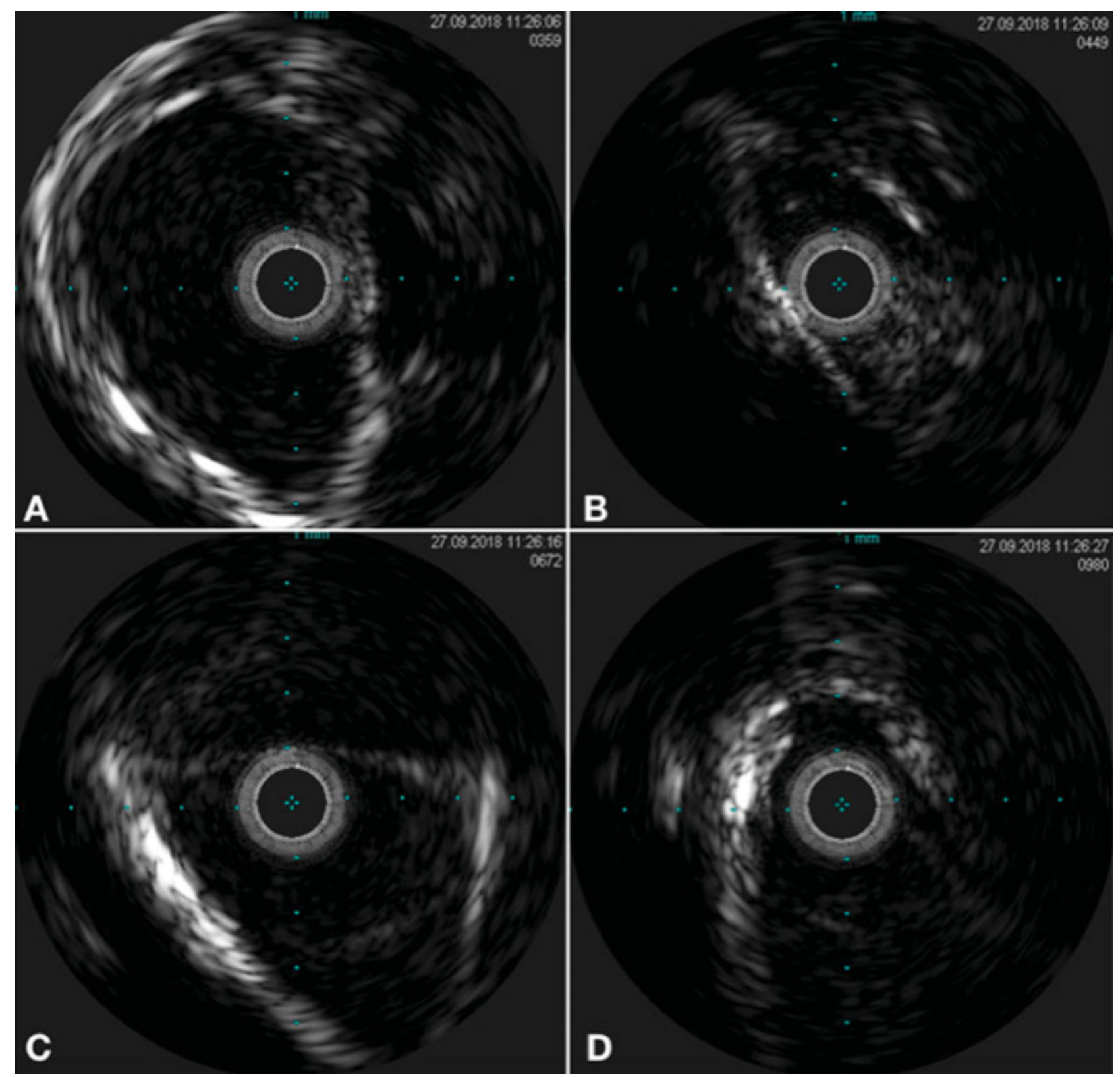

Fig. 2 Images of intravenous ultrasound. Poststenosis left transverse sinus (A). Interior of left transverse sinus stenosis (B). Prestenosis right transverse sinus (C). Interior of right transverse sinus stenosis (D).

\section{Discussion}

The first line of IIH treatment is clinical, and consists of weight reduction, adequate diet, analgesics to relieve headache, and carbonic anhydrase inhibitors such as acetazolamide (1.5 to $3 \mathrm{~g} /$ day divided into 3 or 4 doses) or methazolamide (50 to $300 \mathrm{mg} /$ day); furosemide or topiramate may be used as a second option in some cases. ${ }^{8,9}$ Obesity plays an important role both in the development of IIH and in its refractoriness to treatment. Excess weight is believed to result in increased intrathoracic pressure, which impairs venous drainage of the head and of the neck, consequently leading to an increase in ICP. ${ }^{10}$

Surgical treatment is reserved for cases with symptoms refractory to conservative management or rapid, significant deterioration of visual acuity. The recommended modalities are optic nerve sheath fenestration (ONSF) or shunting (ventriculoperitoneal, lumboperitoneal). ${ }^{11}$ In recent years, venous angioplasty has gained an increasing role in the treatment of this disease, with promising results and low morbidity and mortality, ${ }^{12}$ providing a minimally invasive and highly effective alternative to the usual surgical procedures. Whether dural venous stenosis is a cause or a consequence of IIH remains unknown. The most accepted theory is that intracranial hypertension causes extrinsic compression of the dural venous sinuses. ${ }^{13}$ Venous stenting both relieves this compression and reduces ICP. ${ }^{14}$ Conversely, medical management and CSF drainage have no impact on venous stenosis, even when ICP improves. ${ }^{15}$

In our case, we chose to perform the pressure measurements with conscious sedation because some studies have 


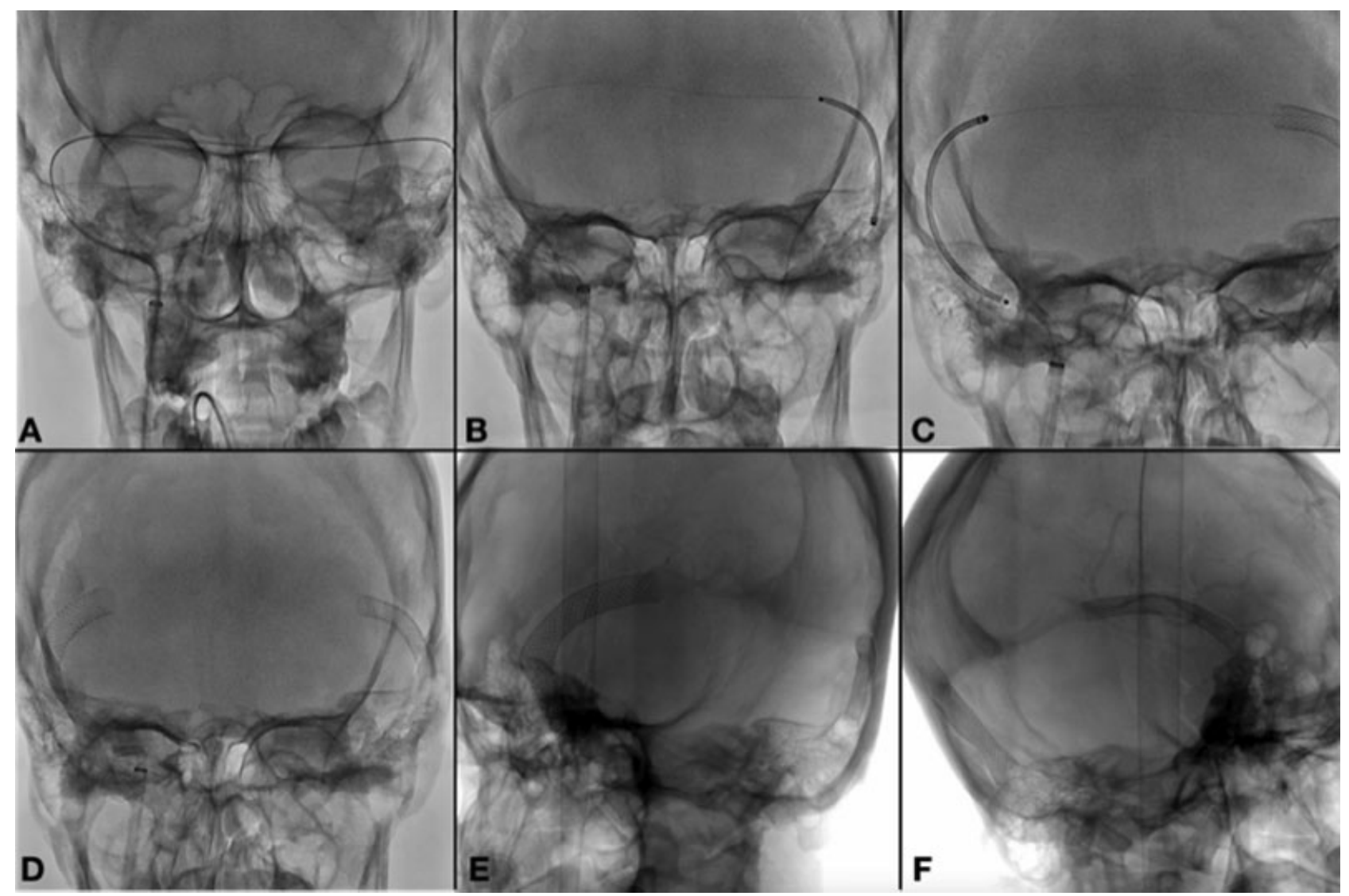

Fig. 3 Step-by-step procedure. $10 \mathrm{~F}$ sheath and $8 \mathrm{~F}$ guide catheter in the right jugular bulb (A). Stent implantation on the left (B). Stent implantation on the right (C). Images of postoperative control (D, E, F).

shown that general anesthesia causes a substantial decrease in the pressure gradient of the venous system, which may bias the results of the procedure. ${ }^{16}$ Once the gradient had been confirmed, we switched to general anesthesia for patient comfort, as manipulation of material within the venous system can cause considerable pain.

In most cases, dural venous stenosis occurs in the transverse sinus, and in between 70 and $80 \%$ of the cases, it is bilateral. This raises another question: should angioplasty be performed bilaterally or only in the dominant sinus? Koovor et $\mathrm{al}^{17}$ described a series of 16 treated patients, of whom $75 \%$ had bilateral transverse sinus stenosis; nevertheless, in all of the cases, only the dominant sinus was treated. Headache improved in 10 patients, and the papilledema improved in all of them. No complications were reported. In our case, although the right transverse sinus was dominant, there was abundant flow to the left, and the pressure gradient on this side was also quite considerable, which is why we chose to place stents bilaterally. From a technical standpoint, it was easy to pass the stent from right to left and to deploy it in the craniocaudal direction, and easier still to then pass the other stent and to treat the stenosis ipsilateral to endovascular access.

Several studies have compared treatment alternatives for dural venous stenosis. A meta-analysis published in $2015^{18}$ compared outcomes in 136 patients who were treated with angioplasty, 712 with ONSF, and 435 with CSF shunt place- ment. In the ONSF group, there was improvement of vision in $59 \%$, of headache in $44 \%$, and of papilledema in $80 \%$. In the CSF shunt group, there was improvement of vision, headache, and papilledema in $54 \%, 80 \%$, and $70 \%$, respectively, while in the angioplasty group, there was improvement of vision, headache, and papilledema in $78 \%, 83 \%$, and $97 \%$, respectively. The complication rates were $18 \%$ in the ONSF group, $40 \%$ in the CSF shunt group, and $7.5 \%$ in the angioplasty group. These findings confirm the greater success and lower complication rates of angioplasty. ${ }^{19}$

- Table 1 describes major case series of patients treated with dural venous angioplasty, demonstrating low rates of complications and high rates of symptomatic improvement. ${ }^{21-27}$ Most of the complications reported were related to vascular access, such as local hemorrhage and pseudoaneurysm, rather than to stent implantation. Ducruet et al, ${ }^{20}$ in their series of 30 cases, reported intrastent stenosis in 4 patients, and proximal stent stenosis in 5 . None of these required new stent implantation, and five patients did undergo CSF shunt placement. A recent meta-analysis ${ }^{28}$ of 473 patients reported restenosis in $14 \%$ of the cases, most of them proximal or distal to the stent. The mechanisms judged most likely by the authors were intimal hyperplasia or simply because extrinsic intracranial hypertension continued to compress the sinuses. Thus, it seems plausible that using longer stents could reduce the rate of restenosis. 
Table 1 Results of case series in the literature

\begin{tabular}{|l|l|l|l|l|l|l|l|}
\hline Study & $\begin{array}{l}\text { Number of } \\
\text { patients }\end{array}$ & $\begin{array}{l}\text { Headache } \\
(\%)\end{array}$ & $\begin{array}{l}\text { Visual } \\
\text { symptoms } \\
(\%)\end{array}$ & $\begin{array}{l}\text { Papilledema } \\
(\%)\end{array}$ & $\begin{array}{l}\text { Opening } \\
\text { presssure } \\
(\mathbf{m m} \text { Hg) }\end{array}$ & $\begin{array}{l}\text { Pain } \\
\text { alleviation } \\
(\%)\end{array}$ & $\begin{array}{l}\text { Complica- } \\
\text { tions }(\boldsymbol{n})\end{array}$ \\
\hline Higgins et al., 2003 & 12 & 100 & 100 & 67 & 33.7 & 42 & 0 \\
\hline Donnet et al., 2008 & 10 & 100 & 80 & 100 & 40.2 & 80 & 0 \\
\hline Bussiere et al., 2010 & 13 & 100 & 77 & 92 & $\mathrm{NR}$ & 100 & 1 \\
\hline Ahmed et al., 2011 & 52 & 83 & & 88 & 32.9 & 85 & 7 \\
\hline Fields, et al., 2013 & 15 & 100 & 100 & 100 & $\mathrm{NR}$ & 67 & 1 \\
\hline Ducruet et al., 2014 20 & 30 & 100 & $\mathrm{NR}$ & 100 & $\mathrm{NR}$ & 70 & 1 \\
\hline Aguilar et al., 2017 & 51 & 74 & 78 & 50 & 35.5 & 84 & 9 \\
\hline Satti et al., 2017 & 43 & 100 & 88 & 65 & $\# 5.8$ & 69 & 0 \\
\hline Shields et al., 2018 & 42 & 100 & 100 & 100 & 38 & 43 & 1 \\
\hline
\end{tabular}

Over the years, the endovascular approach has emerged as the leading treatment modality for $\mathrm{IIH}$, instead of as an alternative to surgery. Cappuzzo et $\mathrm{a}^{29}$ proposed an algorithm whereby, in case of confirmed diagnosis and failure of medical management, or if there is rapid visual deterioration, digital subtraction angiography with pressure gradient measurement should be performed. If a gradient $>8$ $\mathrm{mmHg}$ is present, stenting is indicated; if symptoms recur or if there is no improvement, only then is surgical shunting to be considered. Most of the current literature suggests that failure pos stenting should be treated exactly thus. However, if many patients have bilateral transverse sinus stenosis and the standard treatment is to perform angioplasty only on the dominant side, should this subgroup of patients not benefit from stenting of the other sinus before thinking of surgical shunting? There have been reports ${ }^{27}$ of patients requiring retreatment because of restenosis of the previously treated side, but stenting of the contralateral transverse sinus was not attempted. We believe there is a subgroup of patients that might benefit from bilateral sinus stenting, but comparative studies are needed to support this theory.

\section{Conclusion}

Transverse sinus angioplasty seems to be a safe and relatively simple procedure for the treatment of $\mathrm{IIH}$, with very good short-term outcomes and low complication rates. Additional research is needed to confirm these findings.

Conflicts of Interests

The authors have no conflicts of interests to declare.

\section{References}

1 Puffer RC, Mustafa W, Lanzino G. Venous sinus stenting for idiopathic intracranial hypertension: a review of the literature. J Neurointerv Surg 2013;5(05):483-486

2 Dinkin MJ, Patsalides A. Venous sinus stenting for idiopathic intracranial hypertension: where are we now? Neurol Clin 2017;35(01):59-81

3 Ahmed RM, Wilkinson M, Parker GD, et al. Transverse sinus stenting for idiopathic intracranial hypertension: a review of 52 patients and of model predictions. AJNR Am J Neuroradiol 2011; 32(08):1408-1414

4 Contreras-Martin Y, Bueno-Perdomo JH. Idiopathic intracranial hypertension: descriptive analysis in our setting. Neurologia 2015;30(02):106-110

5 Miller NR. Papilledema. In: Miller NR, Newman NJ, eds. Walsh \& Hoyt's clinical neuro-ophthalmology. Vol. 1. 5th ed. Baltimore: Williams \& Wilkins; 1998:487-548

6 Wall M. Idiopathic intracranial hypertension. Neurol Clin 1991;9 (01):73-95

7 Friedman DI, Liu GT, Digre KB. Revised diagnostic criteria for the pseudotumor cerebri syndrome in adults and children. Neurology 2013;81(13):1159-1165

8 Friedman DI, Jacobson DM. Idiopathic intracranial hypertension. J Neuroophthalmol 2004;24(02):138-145

9 Skau M, Brennum J, Gjerris F, Jensen R. What is new about idiopathic intracranial hypertension? An updated review of mechanism and treatment. Cephalalgia 2006;26(04):384-399

10 Sugerman HJ, DeMaria EJ, Felton WL III, Nakatsuka M, Sismanis A. Increased intra-abdominal pressure and cardiac filling pressures in obesity-associated pseudotumor cerebri. Neurology 1997;49 (02):507-511

11 Wall $\mathrm{M}$, George D. Idiopathic intracranial hypertension. A prospective study of 50 patients. Brain 1991;114( Pt 1A):155180

12 Lenck S, Vallée F, Labeyrie MA, et al. Stenting of the lateral sinus in idiopathic intracranial hypertension according to the type of stenosis. Neurosurgery 2017;80(03):393-400

13 Stevens SA, Stimpson J, Lakin WD, Thakore NJ, Penar PL. A model for idiopathic intracranial hypertension and associated pathological ICP wave-forms. IEEE Trans Biomed Eng 2008;55(2 Pt 1): 388-398

14 Dinkin MJ, Patsalides A. Venous sinus stenting in idiopathic intracranial hypertension: results of a prospective trial. J Neuroophthalmol 2017;37(02):113-121

15 Bono F, Giliberto C, Mastrandrea C, et al. Transverse sinus stenoses persist after normalization of the CSF pressure in IIH. Neurology 2005;65(07):1090-1093

16 Raper DMS, Buell TJ, Chen CJ, Ding D, Starke RM, Liu KC. Intracranial venous pressures under conscious sedation and general anesthesia. J Neurointerv Surg 2017;9(10):986-989

17 Koovor JM, Lopez GV, Riley K, Tejada J. Transverse venous sinus stenting for idiopathic intracranial hypertension: Safety and feasibility. J Neuroradiol 2018;31(05):513-517

18 Satti SR, Leishangthem L, Chaudry MI. Meta-analysis of CSF diversion procedures and dural venous sinus stenting in the setting of medically refractory idiopathic intracranial hypertension. AJNR Am J Neuroradiol 2015;36(10):1899-1904 
19 Chagot C, Blonski M, Machu JL, Bracard S, Lacour JC, Richard S. J Idiopathic intracranial hypertension: prognostic factors and multidisciplinary management. J Obes 2017;2017:5348928

20 Ducruet AF, Crowley RW, McDougall CG, Albuquerque FC. Longterm patency of venous sinus stents for idiopathic intracranial hypertension. J Neurointerv Surg 2014;6(03):238-242

21 Higgins JN, Cousins C, Owler BK, Sarkies N, Pickard JD. Idiopathic Intracranial Hypertension: 12 cases treated by venous sinus stenting. J. Neurol Neurosurg Psychiatry 2003;74:1662-1666

22 Donnet A, Metellus P, Levrier O, Mekkaoui C, Fuentes S, Dufour H, et al. Endovascular treatment of idiopathic intracranial hypertension: clinical and radiologic outcome of 10 consecutive patients. Neurology 2008;70:641-647

23 Bussiere M, Falero R, Nicolle D, Proulx A, Patel V, Pelz D. Unilateral transverse sinus stenting of patients with idiopathic intracranial hypertension. AJNR Am J Neuroradiol 2010;31:645-650

24 Fields JD, Javedani PP, Falardeau J, Nesbit GM, Dogan A, Helseth EK, et al. Dural venous sinus angioplasty and stenting for the treatment of idiopathic intracranial hypertension. J Neurointerv Surg 2013;5:62-68
25 Aguilar-Perez M, Martinez-Moreno R, Kurre W, Wendl C, Bazner $\mathrm{H}$, Ganslandt O, et al. Endovascular treatment of idiopathic intracranial hypertension: retrospective analysis of immediate and long-term results in 51 patients. Neuroradiology 2017; 59:277-287

26 Satti SR, Leishangthem L, Spiotta A, Chaudry MI. Dural venous sinus stenting for medically and surgically refractory idiopathic intracranial hypertension. Interv Neuroradiol 2017;23:186-193

27 Shields LBE, Shields CB, Yao TL, Plato BM, Zhang YP, Dashti SR. Endovascular treatment for venous sinus stenosis in idiopathic intracranial hypertension: an observational study of clinical indications, surgical technique, and long-term outcomes. World Neurosurg 2018;121:e165-e171

28 Saber H, Lewis W, Sadeghi M, Rajah G, Narayanan S. Stent survival and stent- adjacent stenosis rates following venous sinus stenting for idiopathic intracranial hypertension: a systematic review and meta-analysis. Intervent Neurol 2018;7(06):490-500

29 Cappuzzo JM, Hess RM, Morrison JF, et al. Transverse venous stenting for the treatment of idiopathic intracranial hypertension, or pseudotumor cerebri. Neurosurg Focus 2018;45(01):E11 